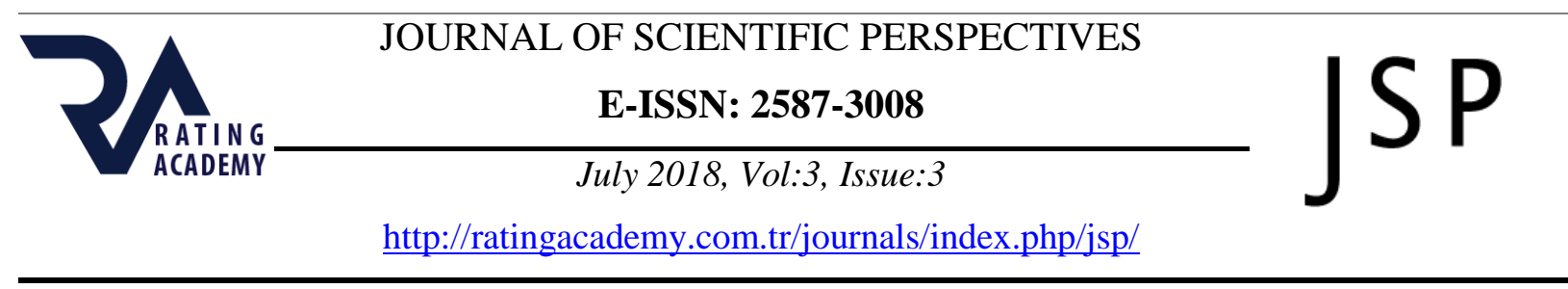

\title{
EUROPEAN TEMPUS TATU PROJECT AND WIRESHARK SOFTWARE IN INDUSTRIAL NETWORKS DATA TRANSFER PROTOCOLS STUDYING AND ANALYZING*
}

\author{
Assoc. Prof. Dr. Vladlen SHAPO \\ National University "Odessa Maritime Academy", Ukraine, \\ E-mail: vladlen.shapo@gmail.com
}

\begin{tabular}{|c|c|}
\hline ARTICLE INFO & ABSTRACT \\
\hline $\begin{array}{l}\text { Article History: } \\
\text { Received: } 19 \text { June } 2018 \\
\text { Accepted: } 25 \text { July } 2018\end{array}$ & \multirow{5}{*}{$\begin{array}{l}\text { Industrial data transfer technologies are implementing in industry, transport, } \\
\text { energetic together with Industry } 4.0 \text { and IIoT concepts. Compatible with } \\
\text { previous generations TCPIIP based protocols ProfiNet, ModBus/TCP, } \\
\text { Ethernet/IP, EtherCAT were created to perform com-plex technical systems } \\
\text { remote control. } \\
\text { In } 2013 \text { - } 2017 \text { European TEMPUS TATU (Trainings in Automation } \\
\text { Technologies for Ukraine) project was realized and TATU Smart Lab (TSL) } \\
\text { equipment was obtained. } \\
\text { TSL is a set of devices for modern automation technologies studying. It matches } \\
\text { to Indus-try } 4.0 \text { and IIoT concepts. It contains programmable logic controllers, } \\
\text { I/O devices, switches, wireless access points and can be used for studying of } \\
\text { Ethernet based data transfer technolo-gies, wireless data transfer, TCP/IP } \\
\text { technologies, hard real-time systems, EtherCAT, CAN, RS232/485, PROFINET, } \\
\text { Modbus TCP interfaces. } \\
\text { WIRESHARK software allows to analyze network traffic and supports capturing } \\
\text { of long network protocols list. It helps to understand the reason of network } \\
\text { problems, simplifies indus-trial and corporate networks exploitation. }\end{array}$} \\
\hline $\begin{array}{l}\text { Keywords: European } \\
\text { Tempus TATU Project, } \\
\text { Wireshark network analyzer, } \\
\text { industrial networks data }\end{array}$ & \\
\hline $\begin{array}{l}\text { transfer protocols, industrial } \\
\text { networks data transfer } \\
\text { protocols studying and } \\
\text { analyzing }\end{array}$ & \\
\hline $\begin{array}{l}\text { DOI: } \\
\text { 10.26900/jsp.2018342247 }\end{array}$ & \\
\hline & \\
\hline
\end{tabular}

\section{INTRODUCTION}

During last 5-7 years in industry, at the different kinds of transport, in energetic field, etc. are very actively implementing data exchange technologies between separate devices, device groups and networks. These technologies based on Industry 4.0 (4th industrial revolution), IoT (Internet of Things), IIoT (Industrial Internet of Things) concepts. In accordance with these concepts a lot of different devices became smart, possessing of own CPUs, memory and different wired and wireless interfaces for external data exchange. Some of them (like complex PLCs) allow to unite different industrial network segments, having sufficient productivity and much lower cost compared to computers (Shapo, URL-1, 2017).

\footnotetext{
* This study is the revised version of the same name paper presented in the "2nd International Rating Academy Congress: Hope" held in Kepez / Çanakkale on April 19-21, 2018.
} 
From the beginning of 90th years of 20th century in industry are very popular some protocols and data transfer technologies, most known are ASI, ProfiBus, FieldBus, HART, ModBus, CAN family, BAC, etc. But in connection with Internet development and forthcoming of absolutely new challenges were created some TCP/IP based protocols, which allow to perform remote control of complex technical systems for enhancement of control quality, decreasing response time for force majeure situations and cost for control and exploitation of such systems. Protocols ProfiNet, ModBus/TCP, Ethernet/IP, EtherCAT became well known; they are compatible with previous generations, but allow to solve fundamentally new tasks. But in some situations by cost/productivity ratio win protocols and technologies, which don't have wide spread, but firmly hold theirs niche. Some of them are described below.

\section{MAIN TEXT}

ACN (Architecture for Control Networks) is network control protocol, initially destined for entertainment industry (URL-2, 2017). It has open source code and maintains some subordinate protocols (table 1).

AYIYA (Anything In Anything) is network protocol for tunneling between IPnetworks and controlling there (URL-3, 2017). Very often it's used for IPv6 packets transit through the networks based on IPv4 protocol. Network security is provided with absence of addresses and content of tunneled packets falsification possibility. At least one of two tunnel endpoints allows mobile devices connecting.

Table 1. ACN protocols family and corresponding standards

\begin{tabular}{|l|l|}
\hline \multicolumn{1}{|c|}{ Protocol } & \multicolumn{1}{c|}{ Standard } \\
\hline $\begin{array}{l}\text { Root Layer, Session Data Transport and Device } \\
\text { Management Protocols, Device Description Language }\end{array}$ & ANSI E1.17 \\
\hline Service Location Protocol (SLP) & RFC 2609 \\
\hline Simple Network Time Protocol (SNTP) & RFC 2030, ANSI E1.30-3-2009 \\
\hline Trivial File Transfer Protocol (TFTP) & RFC 1350 \\
\hline Streaming ACN (sACN) & ANSI E1.31 \\
\hline RDM Extension (RDMNet) & ANSI E1.33 \\
\hline Remote Device Management (RDM) & ANSI E1.20 \\
\hline
\end{tabular}

CIP (Common Industrial Protocol) is the set of standards (URL-4, 2017), which are maintained by Open DeviceNet Vendors Association (ODVA). CIP extensions are CIP safety, CIP Sync and CIP Motion protocols. CIP contains full set of requirements and possibilities for complex automation systems and their subsystems development from following sides: control, information security, motion organizing, informing. Some most important protocols and industrial data transfer technologies are based on CIP as well and briefly described below.

EtherNet/IP is open industry protocol, which uses standard Ethernet chips and cable systems, based on IEEE 802.3 standard, and serve for input/output real time data exchange and information messages in DeviceNet and ControlNet industrial networks. CIP provides common application level between networks, which doesn't depend on media (cable system). It allows to perform direct routing CIP messages in EtherNet/IP, ControlNet and DeviceNet. Depending on application requirements EtherNet/IP network may be stand-alone or combined with DeviceNet or ControlNet networks for additional flexible information and control services realization. EtherNet/IP transfers big user, configuration and input/output data volumes in the same high-speed network; tightly associates technological and corporate operations; facilitates technical maintenance expenses decreasing thanks to existing network 
resources and technical facilities using; allows to commercial and industrial technological levels to coexist in the same network; works with TCP/IP and HTTP protocols.

DNP3 (Distributed Network Protocol, version 3) is a set of communication protocols (URL-5, 2017), which are used for data transfer between components in automation systems like different types of equipment for data acquisition and control and described in IEEE 1815 standard. In SCADA systems DNP3 is used by SCADA master stations (control centers), Remote Terminal Units (RTU) and different Intelligent Electronic Devices (IED). It uses 3 levels of OSI model (data link, transport, application) and contains Secure Authentication v5 mechanism, which allows to master or remote DNP3-system uniquely determine, that connection is established with legitimate user or host, but not with malicious user.

HART-IP (Highway Addressable Remote Transducer) protocol (URL-6, 2017) based on standard Ethernet IEEE 802.3 hardware and cable systems and with Wi-Fi IEEE 802.11 equipment, that's why it's possible to use it with standard network switches, routers, access points. It may be used in redundant mesh or ring topologies and with PoE (Power over Ethernet) power supply standard by twisted pair. Possible data transfer rates are 10 or 100 Mbps and 1 Gbps. HART network, including devices working with Wireless HART protocol, is compatible with office and industrial LAN-switches, fiber optics media converters, Wi-Fi access points and another equipment. Compatibility with classic HART protocol allows to put corresponding gateways into action and to work with classic analogue 4-20 mA technologies. Using IP as base interaction protocol allows HART-IP to work in the same network together with multiplicity of protocols, based on IP and Ethernet. More than 60 millions devices with HART protocol supporting are installed in the world. HART over Ethernet or HART-IP widen HART accessibility in local internal industrial networks with interconnection with corporate networks and ERP (Enterprise Resource Planning) software. Variables and diagnostic data in HART are encapsulated in HART-IP packets. It allows to realize real time processes in existing corporate networks and to use corporate VPN (Virtual Private Networks).

Figure 1. Viewing HART IP protocol packets in Wireshark network analyzer

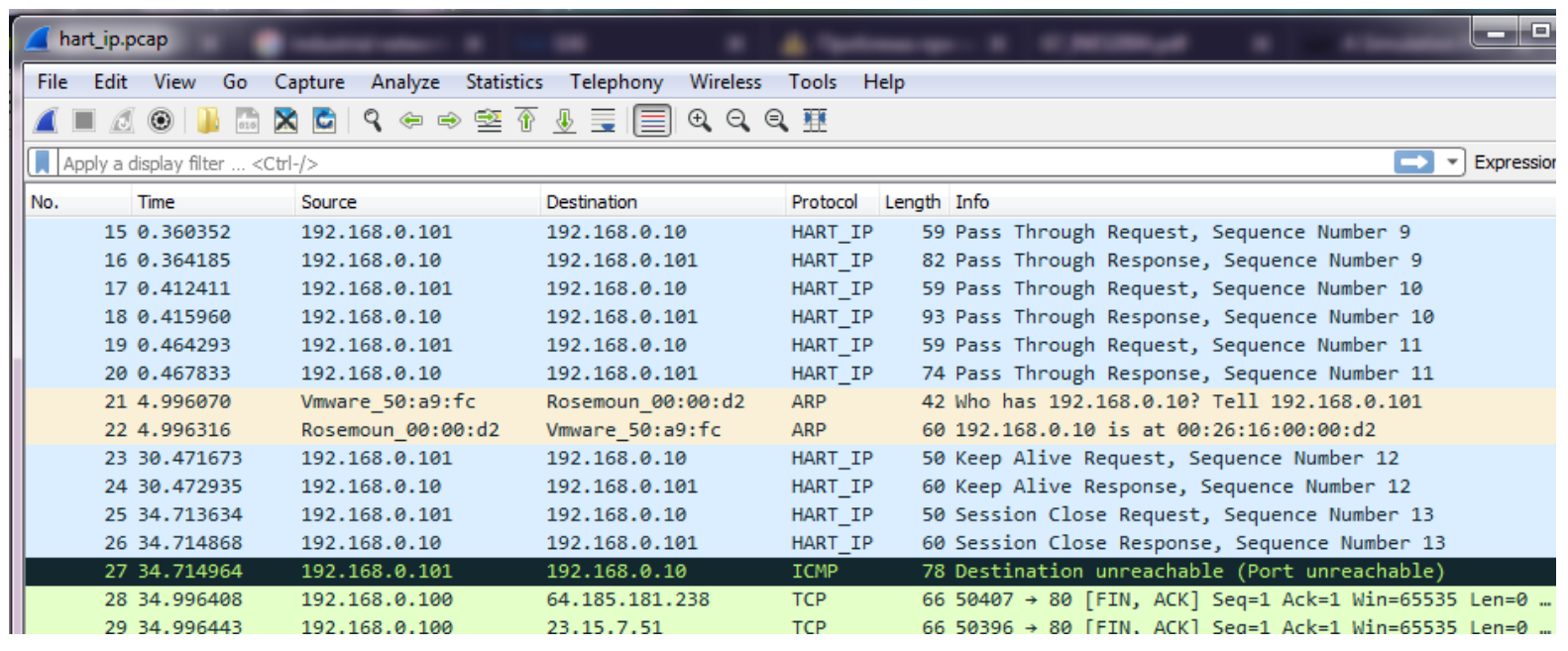

During December 2013 - June 2017 European TEMPUS TATU (Trainings in Automation Technologies for Ukraine) project was realized (URL-7, 2018). Within the framework of this project TATU Smart Lab (TSL) equipment was obtained (Gorb et al, 2017a, 2017b). TSL is a flexibly configurable mobile set of devices for teaching modern automation technologies and its application in real projects. It contains devices from different European manufacturers and matches to goals of Industry 4.0, IoT and IIoT concepts ( 2 hardware modules (HM) of 3 ) where individual devices and their nodes can 
communicate with each other and consumers using wireless data transmission technologies or IP technologies.

The first HM (Fig. 2) contains two programmable controllers (AXC 3050 and ILC 151 GSM/GPRS), PROFINET I/O devices, managed network switch and wireless access point for wireless LAN (Gorb et al, 2017a, 2017b). This HM can be used for studying a wide range of topics including working with data transfer technologies based on Ethernet, wireless data transmission and IP technologies. Two programmable controllers can communicate using TCP/IP or Modbus TCP data transfer protocols. Possible complex industrial IP network structure based on multi interface AXC 3050 smart controller shown at Fig. 3.

Controller EC2250 EtherCAT (Fig. 4), installed in second HM and working with IPbased protocols, has a short cycle time and designed for hard real-time systems [8,9]. The controller uses a high-performance Cortex A9 $800 \mathrm{MHz}$ ARM processor. EtherCAT is an Ethernet based bus standardized by SEMI (Semiconductor Equipment and Materials International), IEC and ISO. EtherCAT is much faster than traditional buses and industrial Ethernet based solutions. The typical EtherCAT cycle time is 50-250 $\mu \mathrm{s}$, while in traditional buses $5-15 \mathrm{~ms}$ are required for each update. The device integrates communication interfaces Ethernet, EtherCAT, CAN, CAN Open, RS232/485, PROFINET, BACnet, Modbus TCP, TCP/IP.

Figure 2. PROFINET hardware module

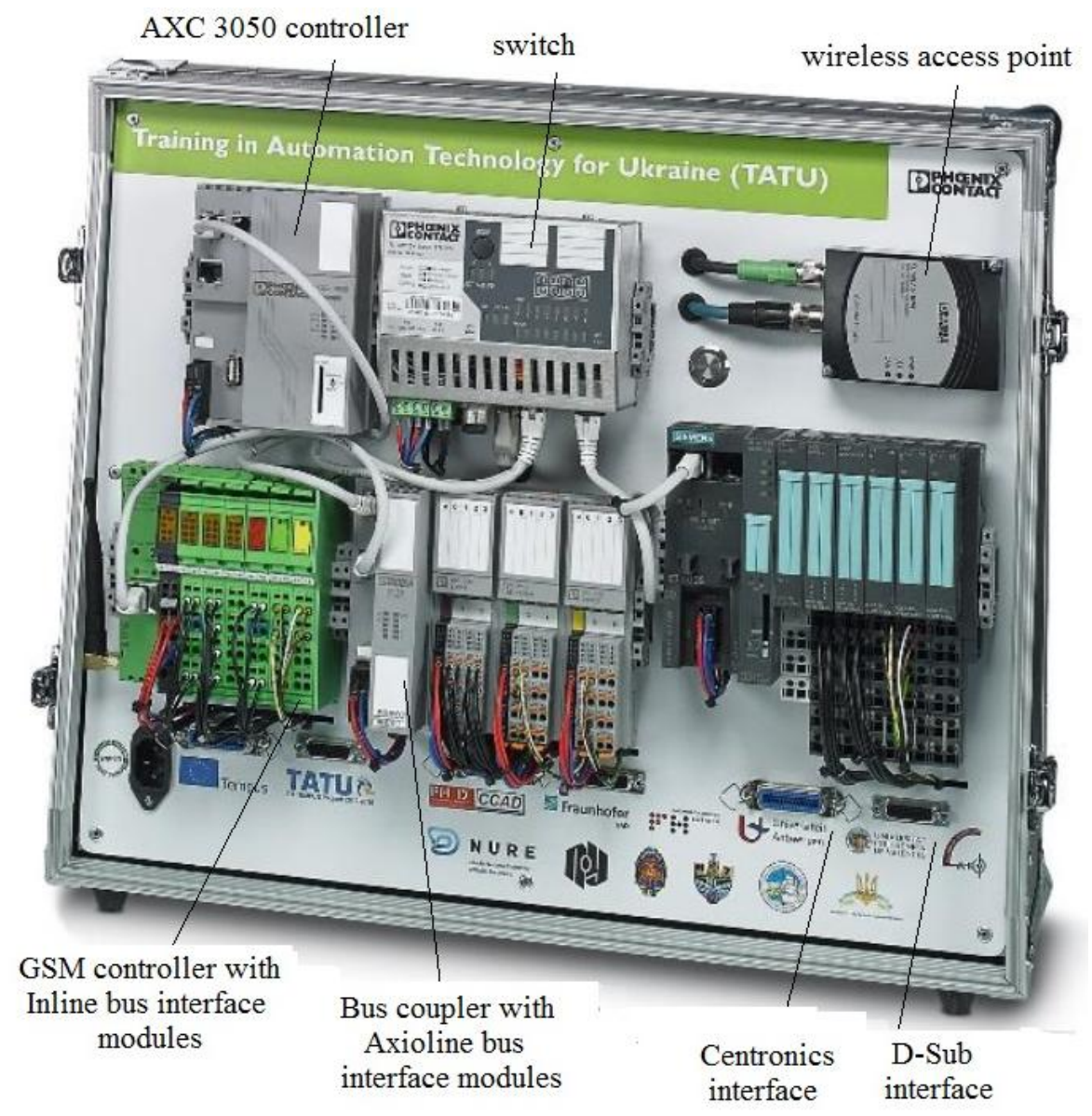


Figure 3. Complex industrial IP network structure based on multi interface controller

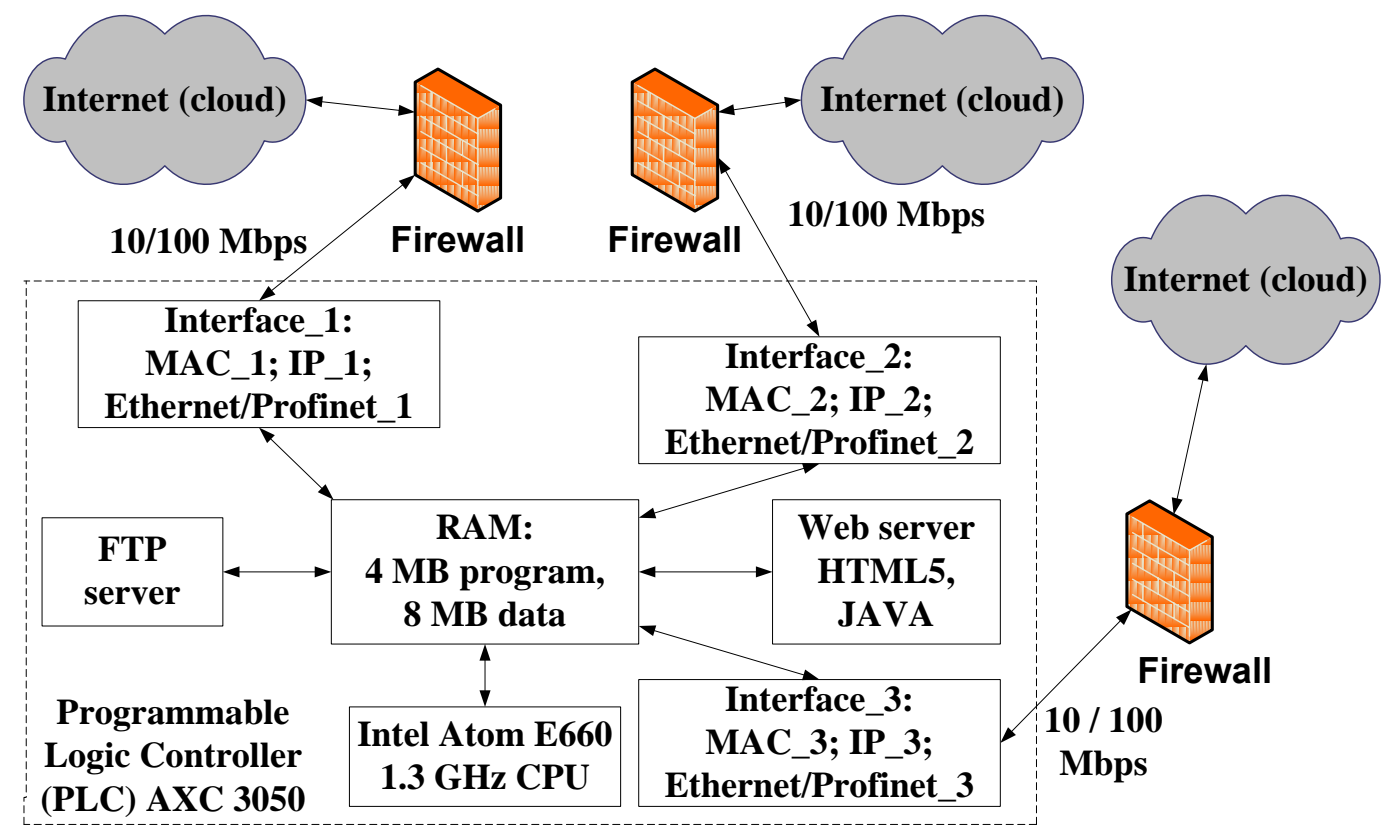

Figure 4. Multi interface industrial IP network controller

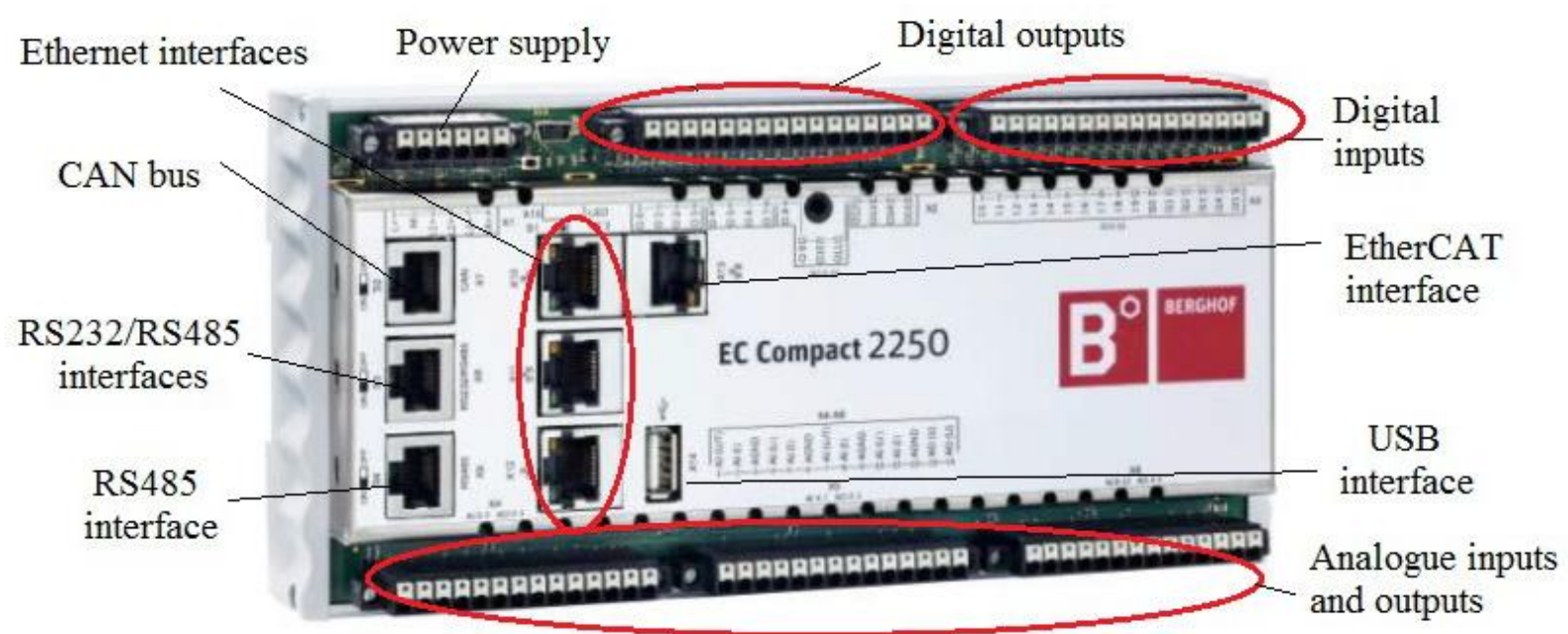

WIRESHARK software allows to analyze network traffic in industrial networks based on protocols and technologies described above. Also Wireshark supports capturing of long list of different network protocols. It significantly helps to understand the reason of unobvious network problems, to simplify complex industrial and corporate networks exploitation and making interconnection between different network technologies and protocols using corresponding hardware and software gateways. 
Figure 5. Viewing EtherCAT protocol packets in Wireshark network analyzer

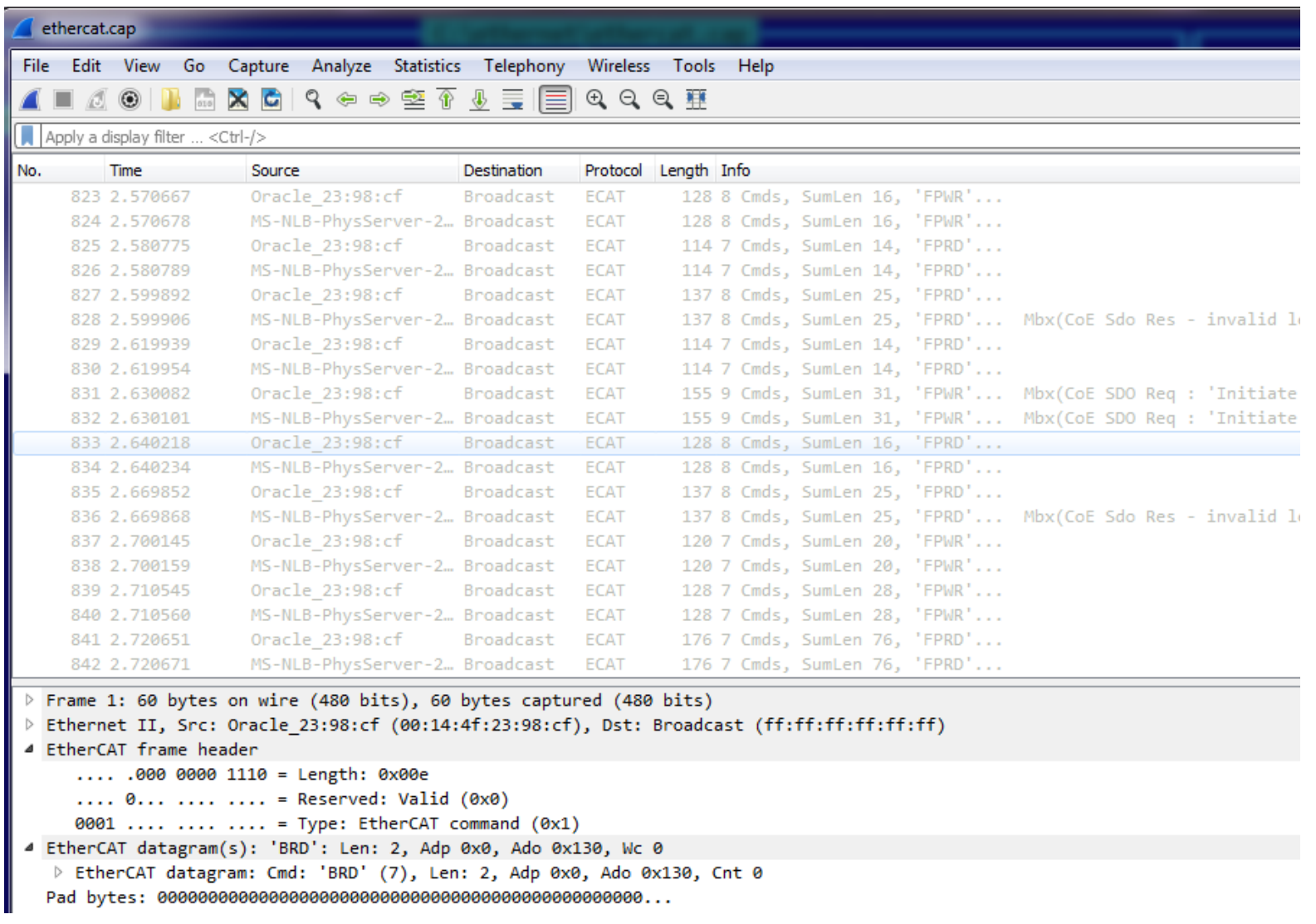

\section{CONCLUSION}

Industrial classic and IP based data transfer protocols and technologies are briefly analyzed. Possibilities of Wireshark network traffic analyzer and examples of industrial networks traffic capturing are shown. Complex industrial IP network structure based on multi interface controller is proposed. Using of equipment, ready for application within the framework of Industry 4.0, IIoT and IoT concepts jointly with Wireshark network traffic analyzer is described. 


\section{REFERENCES}

ARCHITECTURE FOR CONTROL NETWORKS [Electronic resource]: https://acn.codeplex.com [Date Accessed: 2 December 2017].

DISTRIBUTED NETWORK PROTOCOL [Electronic resource]: https://www.dnp.org/AboutUs/DNP3\%20Primer\%20Rev\%20A.pdf [Date Accessed: 2 December 2017].

EUROPEAN TEMPUS TATU PROJECT [Electronic resource]: https://tatu.org.ua [Date Accessed: 2 March 2018].

GORB, S.I., NIKOLSKYI, V.V., SHAPO, V.F., KHNIUNIN, S.H., 2017, Programming controllers in the integrated development environment: training manual. Practice, Odessa: National University "Odessa Maritime Academy", 978-966-7591-73-1.

GORB, S.I., NIKOLSKYI, V.V., SHAPO, V.F., Khniunin, S.H., 2017, TATU study book. Trainings in Automation Technology for Ukraine, Villach: Carinthia University of Applied Sciences, 978-3-9504443-0-8.

INSTRUMENTATION TOOLs [Electronic resource]: http://instrumentationtools.com/whatis-hart-ip/\#.WibYR31x1aQ [Date Accessed: 2 December 2017].

SHAPO, Vladlen, 2017, Programmable Logic Controllers Applying for Multi Segment Industrial Data Transfer Networks Developing [online]: http://medcraveonline.com/IRATJ/IRATJ-03-00060.php [Date Accessed: 2 December 2017].

SixXS - IPv6 Deployment \& Tunnel Broker [Electronic resource]: https://www.sixxs.net/tools/ayiya/ [Date Accessed: 2 December 2017].

THE FUTURE OF INDUSTRIAL AUTOMATION [Electronic resource]: https://www.odva.org/Technology-Standards/Common-Industrial-Protocol-CIP [Date Accessed: 2 December 2017]. 
SHAPO / European Tempus Tatu Project and Wireshark Software 